\title{
Electrochemically driven phase transitions in crystallographically challenged electrode materials for rechargeable batteries
}

\author{
M. A. Karlsen, D. B. Ravnsbæk \\ University of Southern Denmark, Campusvej 55, 5230 Odense M, Denmark \\ maak@sdu.dk
}

Traditionally, electrode materials for intercalation-type rechargeable batteries have been crystalline. For crystalline materials, the material structure on the atomic length scale may be probed through traditional diffraction experiments and structure-property relations may be revealed through operando experiments, where the battery is charged and discharged, while irradiated with a proper probe, e.g. intense high-energy synchrotron x-rays. However, when electrode materials disorder, either during battery operation or are disordered ab origine, the limited range of structural coherence diminishes the amount of structural information extractable through traditional diffraction experiments. To probe the material structure on a more local length scale, total scattering combined with pair distribution function (PDF) analysis may be applied to elucidate the atomic structure on a very local level, even under dynamic conditions through operando experiments. [1-2]

This poster presents selected examples on both irreversible and reversible order-disorder phase transitions, for $\mathrm{TiO}_{2}$-rutile and $\mathrm{Na}_{\mathrm{x}} \mathrm{Fe}_{1.13}\left(\mathrm{PO}_{4}\right)(\mathrm{OH})_{0.39}\left(\mathrm{H}_{2} \mathrm{O}\right)_{0.6}$, respectively. The phase transitions are induced electrochemically by ion-intercalation and iondeintercalation during battery operation. Also, an example on an ab origine nanocrystalline material, $\mathrm{TiO}_{2}$-bronze, is presented. Also for this nanocrystalline material, traditional diffraction methods fall short, when it comes to characterization of the material structure at the atomic length scale. In all three cases presented here, x-ray total scattering and PDF analysis provide unique structural information on the atomic length scale for otherwise crystallographically challenged materials.
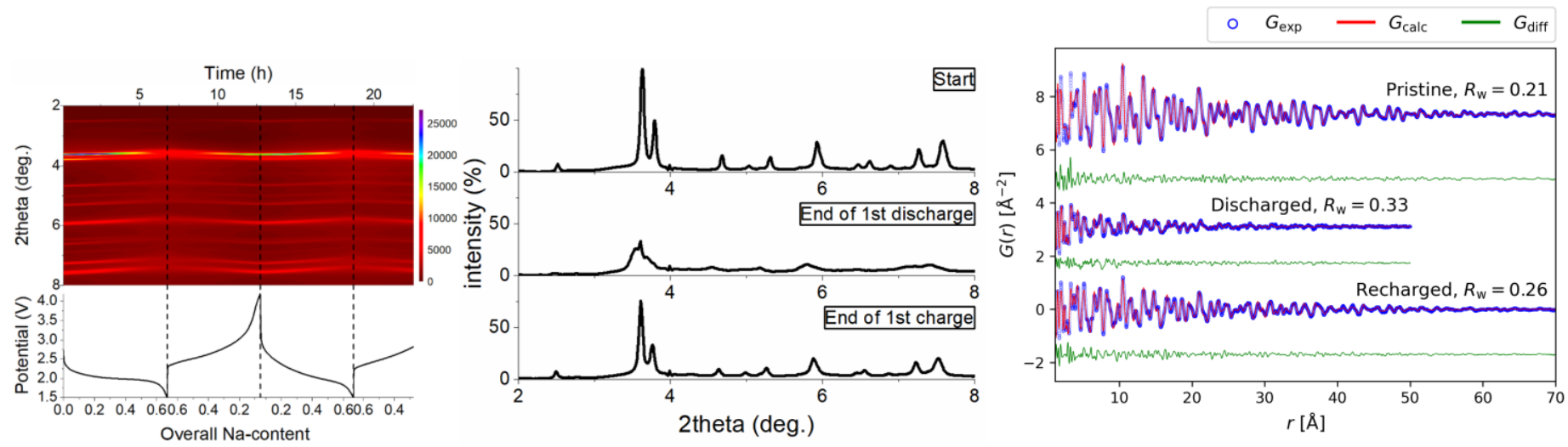

Figure 1. Left: Operando X-ray diffraction of $\mathrm{Na}_{\mathrm{x}} \mathrm{Fe}_{1.13}\left(\mathrm{PO}_{4}\right)(\mathrm{OH})_{0.39}\left(\mathrm{H}_{2} \mathrm{O}\right)_{0.6 .}$. In the upper part, an overview plot of the scattering data is shown, where the scattering angle in degrees and the time in hours are displayed on the axes. In the lower part, the electrochemical data is shown as the voltage as a function of state of charge (overall $\mathrm{Na}$ content). The time and state of charge axes are congruent. Bragg intensity fades during deep discharge but is recovered upon charge. Middle: Ex-situ x-ray diffraction data for the pristine (start), Na-rich (end of 1st discharge), and Na-poor (end of 1st charge) $\mathrm{Na}_{x} \mathrm{Fe}_{1.13}\left(\mathrm{PO}_{4}\right)(\mathrm{OH})_{0.39}\left(\mathrm{H}_{2} \mathrm{O}\right)_{0.6}$ materials. For the Na-rich material, Bragg intensities fade, and broadening is observed to a rather large extent. Right: Fitted reduced atomic pair distribution functions for the pristine (start), Na-rich (end of 1st discharge), and Na-poor (end of 1st charge) $\mathrm{NaxFe}_{1.13}\left(\mathrm{PO}_{4}\right)(\mathrm{OH})_{0.39}\left(\mathrm{H}_{2} \mathrm{O}\right)_{0.6}$ materials. The experimental PDF is shown as blue circles, the calculated PDF as a red curve, and difference curve of the two is shown as a green curve. [3].

[1] Christensen C. K., Sørensen D. R., Hvam J. \& Ravnsbæk D. B. (2019). Nanoscale. 31, 512-520.

[2] Christensen C. K., Mamakhel M. A. Balakrishna A. R., Iversen B. B., Chiang Y.-M. \& Ravnsbæk D. B. (2019). Nanoscale, 11, $12347-12357$.

[3] Henriksen C., Karlsen M. A., Jakobsen C. L. \& Ravnsbæk D. B. (2020). Nanoscale. 12, 12824-12830.

Keywords: Batteries; Operando; Pair Distribution Function Analysis; Order-Disorder Phase Transitions

We acknowledge the Carlsberg Foundation, The Independent Research Fund Denmark, and the instrument center DanScatt for funding.

Acta Cryst. (2021), A77, C1247 